by botanists the world over. So it will be with the Slime Moulds, that are "passing," to be replaced by the Slime Animals.

THE UNIVERSITy OF NeBraska

Charles E. Bessey

\section{SCIENTIFIC JOURNALS AND ARTICLES}

The May number (Vol. 18, No. 8) of the Bulletin of the American Mathematical Society contains the following papers: "Definite integrals containing a parameter," by D. C. Gillespie; "On the $V_{3}^{3}$ with five binodes of the second species in $S_{4}$ " by S. Lefschetz; "What is mathematics" (review of Whitehead and Russell's "Principia Mathematica"), by J. B. Shaw; Review of Bianchi-Lukat's "Differentialgeometrie," by L. P. Eisenhart; "Notes"; "New Publications."

The June number of the Bulletin contains: Report of the April meeting of the Chicago Section, by H. E. Slaught; Report of the twenty-first regular meeting of the San Francisco Section, by T. M. Putnam; "Implicit functions defined by equations with vanishing Jacobian," by G. R. Clements; Review of Darwin's Scientific Papers, by E. W. Brown; Review of Pareto's "Manuel d'Economie politique," by E. B. Wilson; "Notes"; "New Publications."

\section{SPECIAL ARTICLES}

THE LAWS OF PHOTOELECTRIC ACTION AND THE UNITARY THEORY OF LIGHT (LICHTQUANTEN THEORIE)

IN a note which was published in a recent number of ScIence (Vol. 35, p. 783, May 17, 1912) Dr. Karl T. Compton and the writer announced, as the result of experiments, certain conclusions they had come to regarding the relation between the number and kinetic energy of the electrons emitted by different metals under the influence of light, on the one hand, and the frequency of the light and the position of the metals in the voltaic series, on the other. The following brief outline of a method of deducing and extending these laws from theoretical considerations, is not without interest.
Let $N_{v}$ be the number of electrons emitted in unit time by unit area of a metal in the presence of unit density of isotropic radiation of frequency between $v$ and $v+d v$, let $T_{m}$ represent the maximum kinetic energy of these electrons and $T_{v}$ their mean kinetic energy. The writer ${ }^{1}$ has shown that $N_{v}$ and $T_{m}$ have to satisfy equations which can be reduced to

$$
\int_{0}^{\infty} N_{v} h v^{3} e^{-h v \mid R \theta} d v=A_{1} \theta^{2} e^{-w_{0} \mid R \theta}
$$

and

$$
\int_{0}^{\infty} N_{v} T_{m} h v^{3} e^{-h v / R \theta} d v=2 A_{1} R \theta^{3} e^{-w_{0} / R \theta}
$$

In these equations $h$ is Planck's radiation constant, $A_{1}$ is a constant characteristic of the material and independent of the temperature $\boldsymbol{\theta}, w_{0}$ is the internal latent heat of evaporation of one electron at the absolute zero and $R$ is the gas constant reckoned for a single molecule. The following is a solution of equations (1) and (2):

$$
\begin{gathered}
N_{v}=0, \text { for } 0<h v<w_{0}, \\
N_{v}=\frac{A_{1} h}{R^{2} v^{2}}\left(1-\frac{w_{0}}{h v}\right), \text { for } w_{0}<h v<\infty, \\
T_{m}=h v-w_{0}, \text { for } w_{0}<h v<\infty .
\end{gathered}
$$

Equations (1) and (2) have to be slightly modified when reflection of the electrons is taken into account. The result does not appear to make any important difference in (3) and (4) but, instead of (5), we get

$$
T_{v}=s\left(h v-w_{0}\right), \text { for } w_{0}<h v<\infty,
$$

where $s$ is the ratio between the proportion of the incident energy which is absorbed, and the proportion of the incident matter (or electricity), which is absorbed, from the stream of electrons which returns to the body in a state of thermal equilibrium. It can be shown that $s$ lies between zero and unity.

If we define $v_{0}$ by the equation $w_{0}=h v_{0}$ it can easily be shown that the experimental results announced by Dr. Compton and the writer are confirmatory of equations (3), (5) and (6). One of the most interesting consequences of the theory is equation (4) which has not yet been tested by experiment.

${ }^{1}$ Phys. Rev., Vol. 34, February and May, 1912; Phil. Mag., Vol. 23, p. 615, 1912. 
There do not at present appear to be any considerations, either of theory or fact, which would limit the applicability of these laws to the comparatively narrow field to which the term photoelectric effect is usually restricted. For instance, there is no apparent reason why they should not be applicable to the ionization produced by such radiations as the Röntgen and $\gamma$ rays. Moreover the deduction makes no essential use of the fact that the particles have been supposed to be electrically charged; so that similar laws may be expected to characterize the reversible formation of gaseous chemical products under the influence of ætherial radiations.

There is one other point. Equations (1)(6) have been derived without making use of the hypothesis that free radiant energy exists in the form of "Licht-quanten," unless this hypothesis implicitly underlies the assumptions: $(A)$ that Planck's radiation formula is true, $(B)$ that, ceteris paribus, the number of electrons emitted is proportional to the intensity of monochromatic radiation. Planck ${ }^{2}$ has recently shown that the unitary view of the structure of light is not necessary to account for $(A)$ and it has not yet been shown to be necessary to account for $(B)$. It appears therefore that the confirmation of equations (3), (5) and (6) by experiment does not necessarily involve the acceptance of the unitary theory of light.

Palmer Physical Laboratory,

\section{O. W. Richardson} Princeton, N. J.

\section{THE CAPE LOBSTER}

Is noticing the peculiar history of the animal from the Cape of Good Hope, designated under this head, I wish both to correct an error, and at the same time to direct attention to a little known individuality among the higher crustacea.

In a review of Dr. Calman's volume, "The Life of the Crustacea," ${ }^{1}$ this much abused animal was thus referred to:

${ }^{1}$ See ScIence, N. S., Vol. XXXV., No. 892, February 2, 1912.

${ }^{2}$ Ber. der. Deutsch. Physik. Ges., 1912.
We thought that this somewhat shadowy species had never recovered from the aspersions cast upon it by Professor Huxley.

Dr. Calman has kindly called my attention to the fact that the species is really a very substantial shadow, that its nebulous reputation disappeared some years ago, and that Huxley's remarks were not wholly justified in 1878, for the elder Milne Edwards had published a good figure of the animal as early as 1851. Indeed, as we shall see, his still earlier description was based upon an actual specimen.

In my first extended report upon the American lobster ${ }^{2}$ the little Cape species was thus referred to:

A third form, $H$. capensis, has been imperfectly described from the Cape of Good Hope, but it is doubtful if it belongs in this genus.

Such doubt as then existed has since been cleared up, and the species should have been included in my recent work on "The Natural History of the American Lobster." "

The facts regarding the literary history of this neglected species are briefly as follows: It was first figured and described by Herbst under the name of "The Cape Crayfish," Cancer (Astacus) capensis, in 1796, and in a way to puzzle all future students who placed any confidence in his statements. Under the head of "The Cape Crayfish" was this brief description: "Museum Spengler. Astacus, slender, with smooth thorax; claws (manus), hairy, with crenate border; all the legs chelate"; followed by this even more vague and contradictory account:

This beautiful crab (Krebs) occurs at the Cape in mountain streams. It is similar indeed to our common crayfish, but is more slender, and of equal

2 “'The American Lobster: A Study of its Habits and Development,', Bulletin of U. S. Fish Commission for 1895 , p. 8.

${ }^{3}$ Bulletin of the Bureau of Fisheries, Vol. XXIX., Document No. 747, issued July 13, 1911.

4Johann Friedrich Wilhelm Herbst, "Versuch einer Naturgeschichte der Krabben u. Krebse, nebst einer systematischen Beschreibung Arten. B. 2, Krebse,', Tab. XXVI., Fig. 1, and p. 49. Berlin u. Stralsund, 1796. 